\title{
Reliability of clinical tests to evaluate nerve function and mechanosensitivity of the upper limb peripheral nervous system Annina B Schmid*1,5, Florian Brunner ${ }^{2}$, Hannu Luomajoki ${ }^{3}$, Ulrike Held ${ }^{4}$, Lucas M Bachmann ${ }^{4}$, Sabine Künzer ${ }^{1}$ and Michel W Coppieters ${ }^{5}$
}

\begin{abstract}
Address: ${ }^{1}$ Uniklinik Balgrist, Department of Physiotherapy, Forchstrasse 340, 8008 Zurich, Switzerland, ${ }^{2}$ Uniklinik Balgrist, Department of Rheumatology, Forchstrasse 340, 8008 Zurich, Switzerland, 3 Zurich University of Applied Sciences, School of Health Professions, Institute of Physiotherapy, Technikumstrasse 71, 8401 Winterthur, Switzerland, ${ }^{4}$ Horten Center for Patient-Oriented Research, Bolleystrasse 40, Postfach Nord, University of Zurich, Zurich, Switzerland and ${ }^{5}$ School of Health and Rehabilitation Sciences, The University of Queensland, Brisbane, Queensland, Australia

Email: Annina B Schmid* - a.schmid@uq.edu.au; Florian Brunner - florian.brunner@balgrist.ch; Hannu Luomajoki - hannu@physios.ch; Ulrike Held - ulrike.held@usz.ch; Lucas M Bachmann - lucas.bachmann@usz.ch; Sabine Künzer - sabine.kuenzer@balgrist.ch; Michel W Coppieters - m.coppieters@uq.edu.au

* Corresponding author
\end{abstract}

Published: 21 January 2009

BMC Musculoskeletal Disorders 2009, 10:11 doi:10.1186/1471-2474-10-1I
Received: 22 July 2008

Accepted: 21 January 2009

This article is available from: http://www.biomedcentral.com/I47I-2474/I0/II

(C) 2009 Schmid et al; licensee BioMed Central Ltd.

This is an Open Access article distributed under the terms of the Creative Commons Attribution License (http://creativecommons.org/licenses/by/2.0), which permits unrestricted use, distribution, and reproduction in any medium, provided the original work is properly cited.

\begin{abstract}
Background: Clinical tests to assess peripheral nerve disorders can be classified into two categories: tests for afferent/efferent nerve function such as nerve conduction (bedside neurological examination) and tests for increased mechanosensitivity (e.g. upper limb neurodynamic tests (ULNTs) and nerve palpation). Reliability reports of nerve palpation and the interpretation of neurodynamic tests are scarce. This study therefore investigated the intertester reliability of nerve palpation and ULNTs. ULNTs were interpreted based on symptom reproduction and structural differentiation. To put the reliability of these tests in perspective, a comparison with the reliability of clinical tests for nerve function was made.

Methods: Two experienced clinicians examined 31 patients with unilateral arm and/or neck pain. The examination included clinical tests for nerve function (sensory testing, reflexes and manual muscle testing (MMT)) and mechanosensitivity (ULNTs and palpation of the median, radial and ulnar nerve). Kappa statistics were calculated to evaluate intertester reliability. A meta-analysis determined an overall kappa for the domains with multiple kappa values (MMT, ULNT, palpation). We then compared the difference in reliability between the tests of mechanosensitivity and nerve function using a one-sample t-test.

Results: We observed moderate to substantial reliability for the tests for afferent/efferent nerve function (sensory testing: kappa $=0.53$; MMT: kappa $=0.68$; no kappa was calculated for reflexes due to a lack of variation). Tests to investigate mechanosensitivity demonstrated moderate reliability (ULNT: kappa = 0.45 ; palpation: kappa $=0.59$ ). When compared statistically, there was no difference in reliability for tests for nerve function and mechanosensitivity $(p=0.06)$.

Conclusion: This study demonstrates that clinical tests which evaluate increased nerve mechanosensitivity and afferent/efferent nerve function have comparable moderate to substantial reliability. To further investigate the clinometric properties of these tests, more studies are needed to evaluate their validity.
\end{abstract}




\section{Background}

Bedside neurological examination (sensory testing, reflexes and MMT) is used to evaluate lesions of the peripheral nervous system [1]. This assessment screens for nerve injuries characterised by changes in afferent or efferent nerve function such as changes in nerve conduction [2]. Beside these nerve lesions, various other nerve disorders do not necessarily lead to altered afferent or efferent function [3,4]. An inflamed nerve, for example, can be highly sensitive to mechanical stimuli [5], such as compression and stretch, but conduction velocity through the inflamed region can be near normal [6]. Therefore, when relying solely on traditional bedside neurological examination, nerve lesions characterised by increased sensitivity to mechanical stimuli may be overlooked.

With body movements the nervous system slides relative to its surrounding structures and is subject to substantial compression and stretch [7-10]. Whereas a healthy nervous system can tolerate this loading, low levels of stretch and compression are sufficient to generate ectopic impulses from an inflamed nerve $[5,6]$. This increased mechanosensitivity is the key characteristic that is being evaluated in many clinical provocation tests, such as Spurling's test for cervical radiculopathy and the straight leg raising test for lumbar radiculopathy $[11,12]$.

In accordance with the straight leg raising test, neurodynamic tests for the upper limb were designed to evaluate the mechanosensitivity of the brachial plexus and the median, radial and ulnar nerve $[13,14]$. A neurodynamic test is considered positive if symptoms can be reproduced and if symptoms can be altered by structural differentiation [13]. Structural differentiation uses movement at a site remote to the painful area to further load or unload the nervous system $[13,15]$. An example is the addition of ankle dorsiflexion to a straight leg raising test to alter radicular symptoms. The reliability of neurodynamic tests for the upper limb (ULNTs) has been explored widely [1623]. The majority of these studies investigated whether symptom reproduction occurred at a consistent point through range. The overall view is that range of motion measurement at the point of symptom reproduction is reliable.

Although structural differentiation is an important criterion for the interpretation of neurodynamic tests $[24,25]$, to our knowledge, there is only one reliability study that included structural differentiation as one of the criteria for a positive test. Wainner et al. [26] observed substantial intertester agreement (kappa: 0.76 to 0.83 ). A limitation of this study is that a change in symptoms with structural differentiation was not an essential criterion for a test to be considered positive. A test was also positive if only symptoms were reproduced or if a side difference in range of motion was observed. As such, there is no study available that investigates the reliability of the interpretation of neurodynamic tests with structural differentiation as an essential criterion.

Beside ULNTs, nerve palpation has also been proposed to investigate the mechanosensitivity of the nervous system $[25,27]$. To our knowledge, only one study has examined the intertester reliability of this method. Jepsen et al. [28] demonstrated moderate to substantial reliability for palpation of the nerves of the upper limb. Additional studies to test the reliability of nerve palpation are required.

The aim of this study was to evaluate the intertester reliability of nerve palpation and the reliability of the interpretation of ULNTs when symptom reproduction and structural differentiation are considered essential criteria. Although ULNTs are the equivalent of the straight leg raise for the upper limb, ULNTs are in our opinion less commonly used and not as frequently performed as the bedside neurological examination. This might be due to the fact that ULNTs are somewhat more complex to perform, which may impact on their reliability. To put the tests for mechanosensitivity in perspective, a comparison with the reliability of the clinical tests for afferent and efferent nerve function was made.

\section{Methods \\ Participants}

Thirty one patients (15 men and 16 women) were recruited from the Rheumatology and Physiotherapy Department of the Balgrist University Hospital in Zurich, Switzerland. Sample size calculation was based on identifying a moderate strength of agreement at a significance level of 0.05 and a power of $80 \%$ [29].

Patients were included if they presented with unilateral, non-acute arm and/or neck pain ( $\geq 1$ months duration) and were between 18 and 60 years old (mean age 44 (SD \pm 11.5 years $)$ ). Patients were excluded if they had underlying diseases, such as diabetes mellitus, widespread neurological disorders, upper limb/spinal surgery or significant trauma in the preceding 3 months, spinal cord or cauda equina signs, cancer or inflammatory disorders.

The patients presented with 14 different clinical diagnoses as defined by their general practitioners (Table 1). The median symptom duration was 10 months. Approval was obtained from the Ethics Committee of Balgrist University Hospital. All patients gave written consent to participate in the study.

\section{Examination}

The examination consisted of three parts which were performed in a standardised order: (1) bedside neurological 
Table I: Included diagnoses

\begin{tabular}{ll}
\hline Diagnosis* & Number of cases \\
\hline Cervical radiculopathy & 2 \\
Cervical disc herniation & 2 \\
Nonspecific neck pain & 4 \\
Nonspecific arm pain & 6 \\
Rotator cuff tear & 2 \\
Biceps and supraspinatus tendinopathy & I \\
Shoulder impingement & 2 \\
Persistent pain after proximal ulnar fracture & 1 \\
Neurolysis of the ulnar nerve at elbow & 1 \\
Cubital tunnel syndrome & 1 \\
Lateral epicondylalgia & 2 \\
Nonspecific paraesthesia in the hand & 1 \\
Nonspecific wrist pain & 3 \\
Carpal Tunnel Syndrome & 3 \\
\hline
\end{tabular}

*Diagnosis as referred by general practitioners, based on clinical findings, supported with imaging techniques where required.

examination, (2) ULNTs for the median (two most commonly used variants), radial and ulnar nerve, and (3) palpation of the peripheral nerves.

\section{Bedside neurological examination}

Bedside neurological examination consisted of manual muscle tests, sensory testing and reflex testing. MMTs were performed for the myotomes C4 to T1 (C4: upper trapezius; C5: middle deltoid; C6: biceps brachii; C7: triceps brachii; C8: extensor hallucis longus; T1: palmar interossei). All MMTs were performed using the methods described by Kendall and McCreary [30]. Muscle strength was rated as normal or decreased.

Sensory testing evaluated sensitivity for light touch. It was examined from the dermatome $\mathrm{C} 4$ downwards with tissue paper which was moved circumferentially around the patient's upper and lower arm. Each finger was examined separately. The patients compared the sensation in the affected arm with the sensation in the unaffected arm [1]. Sensory testing of the upper limb was rated as normal or abnormal (heightened or diminished sensation). Upon detection of abnormal sensation, the investigators mapped the area and classified the findings as dermatomal or non-dermatomal using a dermatome and sensory innervation chart of the upper limb [30].

Reflexes of the biceps (C5-6) and triceps (C7-8) were tested bilaterally using a standard reflex hammer [31]. Each reflex was graded as reduced/absent, normal or increased compared to the unaffected side.

\section{Upper limb neurodynamic tests}

ULNTs for the median nerve (ULNT MEDIAN(1) $_{\text {I }}$ and ULNT MEDIAN(2a) $)$, radial ( $\left.\mathrm{ULNT}_{\text {RADIAL(2b) }}\right)$ and ulnar nerve $\left(\mathrm{ULNT}_{\mathrm{UL}}\right.$ $\operatorname{NAR}(3)$ ) were performed according to the operational definition described by Butler [25] (see Figure 1). The patient was positioned supine without a pillow. The hand of the untested side rested on the participant's abdomen. All ULNTs were performed with a standardised sequence (see Table 2). Movements were performed to the end of range or until symptoms were produced.

Prior to performing the tests, the patients were instructed to communicate the onset of any sensation such as stretch, tingling or pain anywhere in the arm or neck. Once such a sensation was provoked, structural differentiation between neurogenic and non-neurogenic sources of pain was performed by the addition of sensitising movements at a site distant to the pain. The therapist could choose from the following sensitising movements: ipsiand contralateral cervical lateral flexion, wrist extension or wrist flexion, or shoulder girdle elevation. If the patient's response was unclear, more than one of these sensitising movements were used.

Every test was performed on the unaffected arm first. These findings were then used as a reference for the affected side. An ULNT was considered positive if it reproduced the patient's symptoms at least partially and if structural differentiation supported a neurogenic source. The order of the four ULNTs was randomly assigned using randomisation software [32].

Table 2: ULNT sequencing

\begin{tabular}{|c|c|c|c|c|c|c|}
\hline & $\mathrm{I}$. & 2. & 3. & 4. & 5. & 6. \\
\hline ULNT $T_{\text {MEDIAN(I) }}$ & $\begin{array}{l}\text { Shoulder girdle } \\
\text { fixation }\end{array}$ & Shoulder abduction & Wrist extension & Supination & $\begin{array}{l}\text { Shoulder external } \\
\text { rotation }\end{array}$ & Elbow extension \\
\hline ULNT $_{\text {MEDIAN(2a) }}$ & $\begin{array}{l}\text { Shoulder girdle } \\
\text { depression }\end{array}$ & Elbow extension & $\begin{array}{l}\text { Shoulder external } \\
\text { rotation }\end{array}$ & Supination & Wrist extension & Shoulder abduction \\
\hline ULNT $_{\text {RADIAL(2b) }}$ & $\begin{array}{l}\text { Shoulder girdle } \\
\text { depression }\end{array}$ & Elbow extension & $\begin{array}{l}\text { Shoulder internal } \\
\text { rotation }\end{array}$ & Pronation & Wrist flexion & Shoulder abduction \\
\hline ULNT $_{\text {ULNAR(3) }}$ & Wrist extension & Pronation & Elbow flexion & $\begin{array}{l}\text { Shoulder external } \\
\text { rotation }\end{array}$ & $\begin{array}{l}\text { Shoulder girdle } \\
\text { depression }\end{array}$ & Shoulder abduction \\
\hline
\end{tabular}




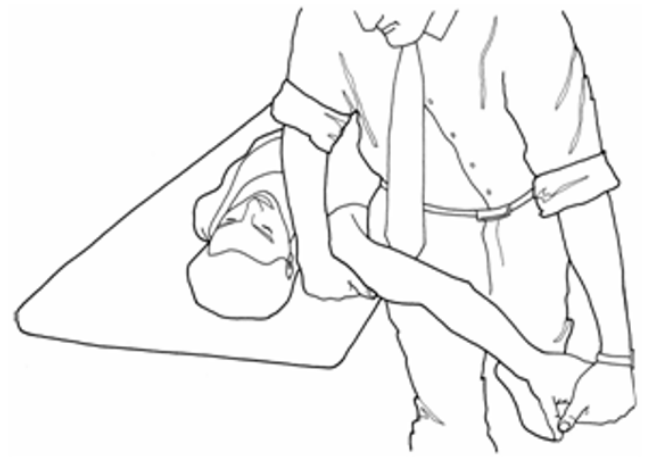

ULNT $T_{\text {MEDIAN (1) }}$

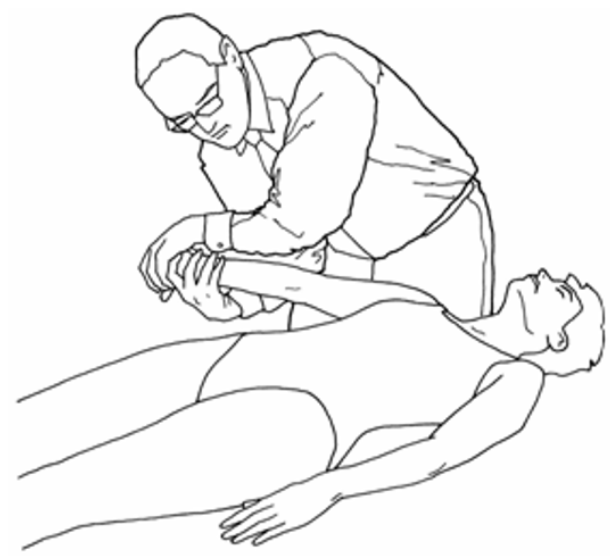

ULNT $T_{\text {RADIAL (2b) }}$

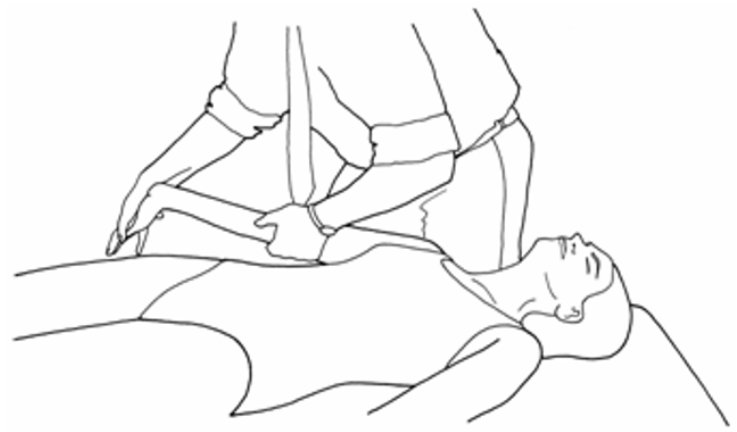

ULNT MEDIAN (2a) $_{\text {ME }}$

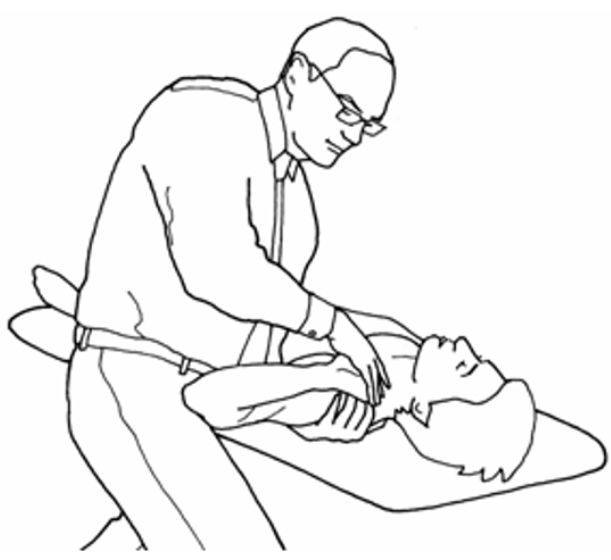

ULNT ULHAR(3) $_{\text {ULA }}$

Figure I

End positions of upper limb neurodynamic tests. Reprinted from Butler DS, The Sensitive Nervous System, Unley, DC, Australia: NOlgroup Publications, 2000, with kind permission.

\section{Nerve palpation}

At least one proximal and one distal site along the radial, ulnar and median nerve were palpated with light to moderate pressure in random order. The palpated sites were chosen in regards to the accessibility of the nerve and involved the median nerve in the upper arm and the wrist, the radial nerve in the upper arm, at the distal radius and in the anatomical snuff box and the ulnar nerve in the upper arm and in the ulnar groove at the elbow (see Figure 2 ). Palpation was rated positive if pain or symptoms were elicited that were different to the unaffected side.

\section{Procedure}

Bedside neurological examination, ULNTs and palpation were conducted by two experienced physiotherapists spe- cialised in musculoskeletal therapy who were blinded to the patients' diagnoses. The investigators underwent 2 hours of training prior to the experiment in order to be familiar with the test performance and rating criteria. Both investigators examined each participant for 30 minutes. There was a break of 60 minutes between the two testing sessions to minimise a testing bias of the first on the second examination. The order of the two therapists was randomly allocated using a randomisation software [32]. Prior to testing, each investigator recorded the participant's current pain intensity on a visual analogue scale (VAS: 0-100) to verify whether pain intensity was comparable at the start of the two testing sessions. 


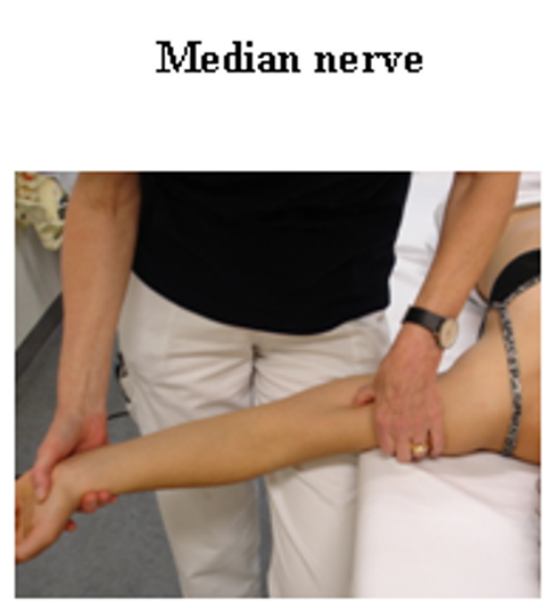

Upper arm

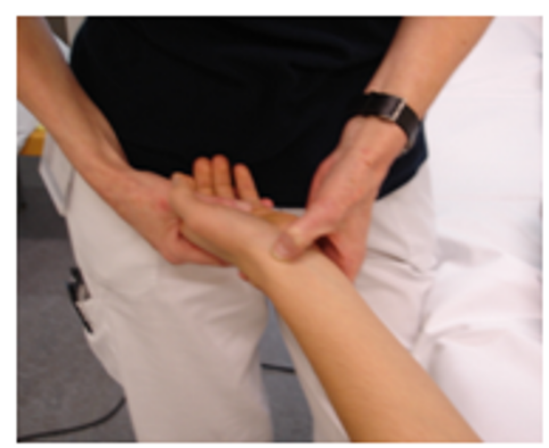

Wrist

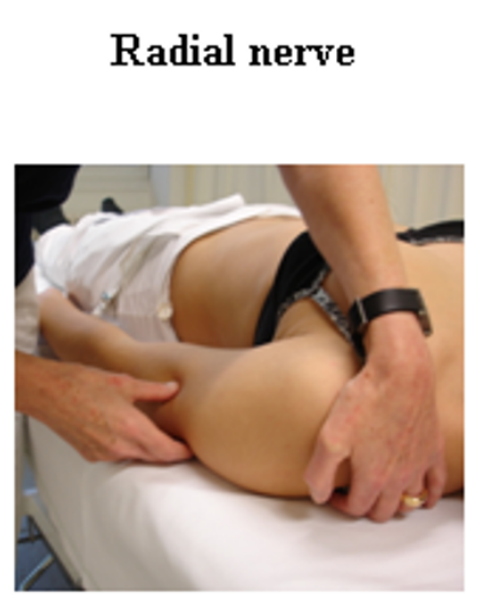

Upper arm

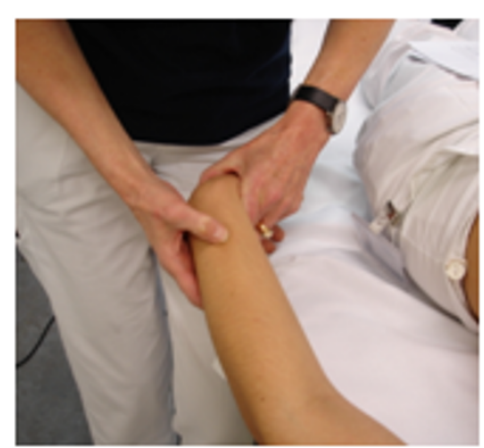

Distal radius

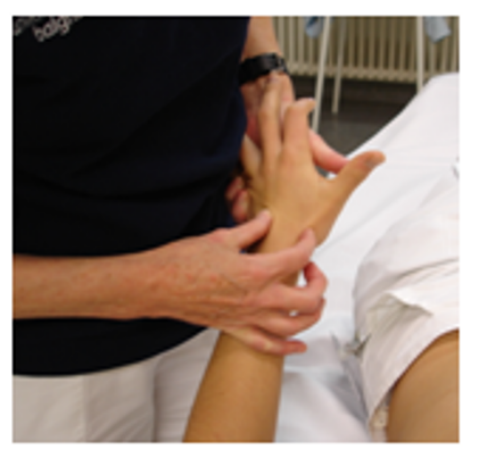

Snuff box
Unnar nerve

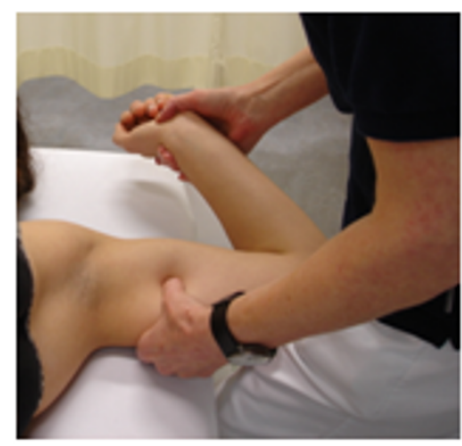

Upper arm

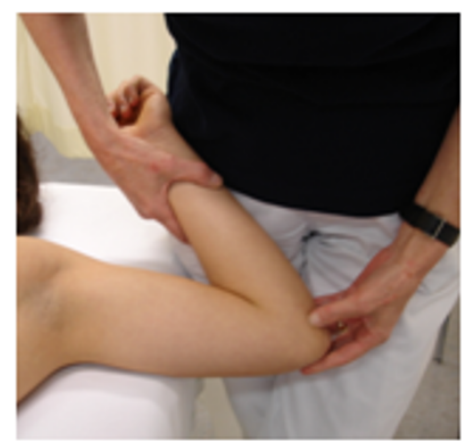

Cubital tunnel

Figure 2

Peripheral nerve palpation points. 
The order of the bedside neurological examination, ULNTs and nerve palpation within each patient was the same for both testing sessions to ensure that a potential order effect was similar between testers.

We were interested in the reliability of the tests in isolation, i.e., irrespective from findings of a thorough patient interview or other clinical tests. Therefore, a separate clinician (rheumatologist) performed a brief patient interview and screened for any exclusion criteria. He then gave the patients concise explanations on the test procedure and familiarised them with neurodynamic tests by performing a straight leg raise with the addition of ankle dorsiflexion. Additionally, he determined joint range of motion of the upper limb and neck. The two investigators received information on symptom location and maximal joint range of motion. Joint range of motion is normally assessed before ULNT performance to identify possible joint stiffness which could affect the available range of motion during ULNTs.

\section{Statistical analysis}

Kappa coefficients and standard errors [33] were calculated for each clinical test. Only test results of the affected side were used to avoid artificially inflated kappa values. Kappas were only computed for tests that had sufficient variability in their results [33]. The classification system proposed by Landis and Koch [34] was used to determine the level of reliability (poor: kappa smaller than zero; slight: zero to 0.20 ; fair: 0.21 to 0.40 ; moderate: 0.41 to 0.60 ; substantial: 0.61 to 0.80 ; almost perfect: 0.81 to $1.00)$.
A meta-analysis was performed to obtain an overall kappa value for those domains with multiple kappa values (MMT, ULNTs and palpation) by pooling the kappa values using a fixed effects model.

The difference between the kappas of the various domains was tested using a t-test with the level of significance set at $5 \%$ and ignoring the dependence of the samples. Statistical analysis was performed using Stata version 9.2 (4905 Lakeway Drive, College Station, USA).

\section{Results}

The mean pain intensity at the start of the first session was $17.2 / 100$ and $16.7 / 100$ for the second session. There was no difference in the two VAS scores (paired t-test, $\mathrm{p}=$ 0.78 ), which demonstrates that the pain level at the start of each examination session was similar.

The frequency of positive ratings for each test is presented in Table 3. Sensory testing was positive in $42 \%$ of the patients (13\% dermatomal; $29 \%$ non-dermatomal distribution). The frequency for a positive MMT for a specific level varied from $0-19 \%$. The frequency for a positive ULNT was $31-39 \%$ depending on the variant and $13 \%-$ $26 \%$ for the different palpation sites. No patient had abnormal biceps or triceps reflexes or positive MMT for C4.

Most tests showed moderate to substantial kappa values (see Table 3). Only palpation of the ulnar nerve in the upper arm and ULNT $\mathrm{ULNAR}_{\text {(3) }}$ revealed fair agreement. MMTs for T1 and C6 demonstrated excellent intertester

Table 3: Frequency of positive findings and the reliability of clinical examination items

\begin{tabular}{|c|c|c|c|c|c|c|c|}
\hline \multirow{2}{*}{$\begin{array}{l}\text { Test } \\
\text { MMT }\end{array}$} & \multicolumn{2}{|c|}{ Frequency } & \multirow{2}{*}{$\begin{array}{c}\text { Kappa } \\
\text { (Standard error) }\end{array}$} & \multirow{2}{*}{$\begin{array}{l}\text { Test } \\
\text { PALPATION }\end{array}$} & \multicolumn{2}{|r|}{ Frequency } & \multirow{2}{*}{$\begin{array}{c}\text { Kappa } \\
\text { (Standard error) }\end{array}$} \\
\hline & & & & & & & \\
\hline $\mathrm{C} 4$ & $0 / 31$ & $0 \%$ & NA & Median, upper arm & $7 / 31$ & $22.6 \%$ & $0.50(0.18)$ \\
\hline $\mathrm{C} 5$ & $4 / 31$ & $12.9 \%$ & $0.53(0.18)$ & Median, wrist & $6 / 31$ & $19.4 \%$ & $0.79(0.18)$ \\
\hline $\mathrm{C} 6$ & $6 / 31$ & $19.4 \%$ & $0.90(0.18)$ & Radial, upper arm & $8 / 31$ & $25.8 \%$ & $0.66(0.18)$ \\
\hline$C 7$ & $2 / 31$ & $6.5 \%$ & $0.45(0.15)$ & Radial, distal radius & $5 / 31$ & $16.1 \%$ & $0.67(0.18)$ \\
\hline $\mathrm{C} 8$ & $2 / 31$ & $6.5 \%$ & $0.64(0.17)$ & Radial, snuff box & $4 / 31$ & $12.9 \%$ & $0.61(0.18)$ \\
\hline \multirow[t]{2}{*}{ TI } & $2 / 31$ & $6.5 \%$ & $1.00(0.18)$ & Ulnar, upper arm & $4 / 31$ & $12.9 \%$ & $0.36(0.16)$ \\
\hline & & & & Ulnar, cubital fossa & $5 / 31$ & $16.1 \%$ & $0.59(0.18)$ \\
\hline \multicolumn{8}{|c|}{ SENSORY TESTING } \\
\hline Dermatomal & $4 / 31$ & $12.9 \%$ & $0.53(0.13)$ & & & & \\
\hline \multirow[t]{2}{*}{ Non-dermatomal } & $9 / 31$ & $29.0 \%$ & & & & & \\
\hline & & & & & & Meta-analysis & Kappa $(95 \%$ Cl) \\
\hline \multicolumn{8}{|l|}{ ULNT } \\
\hline$U_{\text {UNNT }}$ & ||$/ 3 \mid$ & $35.5 \%$ & $0.54(0.18)$ & & & MMT & $0.68(0.53,0.83)$ \\
\hline$U_{\text {ULEIAN(2a) }}$ & ||$/ 3 \mid$ & $35.5 \%$ & $0.46(0.18)$ & & & ULNT & $0.45(0.27,0.63)$ \\
\hline ULNT $_{\text {RADIAL(2b) }}$ & $10 / 31$ & $31.3 \%$ & $0.44(0.18)$ & & & Palpation & $0.59(0.46,0.72)$ \\
\hline ULNT & $|2 / 3|$ & $38.7 \%$ & $0.36(0.18)$ & & & & \\
\hline
\end{tabular}

ULNT: Upper limb neurodynamic test, MMT: Manual muscle test, $\mathrm{Cl}$ : confidence interval 
reliability. Since there were no abnormal findings for reflexes and MMT for $\mathrm{C} 4$, no reliability coefficient was computed for these variables.

The meta-analysis revealed a substantial intertester reliability for MMTs (overall kappa: 0.68; 95\%CI: 0.53 - 0.83), a moderate reliability for ULNT (overall kappa 0.45; 95\%CI: $0.27-0.63$ ) and a moderate reliability for nerve palpation (overall kappa: 0.59; 95\%CI: 0.46 - 0.72). Comparison of these results revealed no statistically significant difference in intertester reliability between test domains (MMT vs. ULNT $\mathrm{p}=0.06$, MMT vs. palpation $\mathrm{p}$ $=0.29$, sensory testing vs. ULNT $\mathrm{p}=0.35$, sensory testing vs. palpation $\mathrm{p}=0.37$ ).

\section{Discussion}

The findings of this study demonstrate that clinical tests to assess peripheral nerve injuries have moderate to substantial reliability when performed in patients who are referred with various neuromusculoskeletal conditions. Clinical tests for afferent and efferent nerve function showed moderate to substantial reliability and tests for increased mechanosensitivity (palpation and ULNTs) demonstrated moderate reliability. When compared statistically, there was no difference in the level of reliability for clinical tests for afferent/efferent nerve function and mechanosensitivity. The results of this study demonstrate that these clinical tests have a satisfactory level of reliability.

With respect to the reliability of ULNTs, most studies investigated whether symptoms occur at a consistent point in range [16-23]. These studies indicated that there is no difference in range of motion when different testers performed the tests. When appropriate reliability coefficients were reported, good to excellent values were observed for ULNTs both in a clinical and laboratory setting [20-23]. Other studies used symptom reproduction as the positive test criterion $[35,36]$. These studies showed only fair intertester reliability (kappa: $0.35-0.38$ ). This discrepancy in reliability might not only be explained by the use of a different criterion, but the authors also suggested that poor test standardisation may have affected the outcome $[35,36]$. In addition, the ULNT MEDIAN(1) $_{\text {per- }}$ formed in the study by Vikarii-Juntura followed the earliest test description, which included elbow flexion rather than extension to load the median nerve [36]. This difference in test performance may also have had an impact on reliability.

Wainner et al. $[26,37]$ reported substantial to almost perfect reliability for the interpretation of the ULNT MEDIAN(1) and $\mathrm{ULNT}_{\text {RADIAL(2b) }}$ (kappa $=0.76$ and 0.83 , respectively). Although these authors used structural differentiation as one of three test criteria, a test could be rated as positive when the patients' symptoms were provoked with the test or when differences in range of motion were detected regardless of the outcome of structural differentiation. Hence, structural differentiation in line with a neurogenic source was not an essential criterion for the test to be considered positive.

In our study, structural differentiation was specifically included as an essential criterion to interpret ULNT outcomes. This may have introduced another source of variation, which may explain the somewhat lower reliability in our study compared to the findings by Wainner et al. [26]. However, structural differentiation is important to limit the amount of false positive results $[38,39]$ and should in our opinion be included when interpreting ULNTs. Another difference between the two studies is the patient sample. Wainner et al. [26,37] only included patients referred to electrophysiological examination with suspected carpal tunnel syndrome or cervical radiculopathy. In the present study, we included patients referred with varying neuromusculoskeletal diagnoses. Although the two samples are markedly different, both are representative for patients in whom ULNTs are performed.

The reliability of individual nerve palpation tests was moderate to substantial. Interestingly, for both the median and ulnar nerve, there was a trend that palpation at distal sites was more reliable than palpation at proximal sites. However, this was not the case for the radial nerve. The level of reliability for nerve palpation observed in this study is similar to the results reported by Jepsen et al. [40] who also demonstrated moderate to substantial intertester reliability (kappa: $0.47-0.69$ ).

Although bedside neurological examination is widely used by health professionals, its intertester reliability has been investigated scarcely in the type of patients commonly seen in a musculoskeletal clinic. Most studies demonstrated only slight to moderate reliability $[26,36,40$ 43]. Our findings for sensory testing are in accordance with previous results [36]. However, our moderate to substantial findings for MMTs are higher than previously reported [26,36,43]. Jepsen et al. [43] used a 6 level scale to rate MMTs and Viikari-Juntura [36] a 3 level scale. We only used 2 levels in rating MMTs which may account for the higher reliability found in our study. However, Wainner et al. [26] reported lower reliability for MMTs using a similar 2-level scale. We assume that Wainner's population, which included a high percentage of patients with electrodiagnostically proven carpal tunnel syndrome and mild cervical radiculopathy, had a higher incidence of muscle weakness than our population. The fact that sensitivity of MMTs has been shown to be lower with small strength deficits [44] may explain the lower reliability in the study by Wainner et al. [26]. 
Several factors should be considered when interpreting the level of reliability found in this study. First of all, we did not use pressure algometry to measure and standardise palpation pressure. Manual palpation was chosen to closely replicate clinical practice. The reliability of palpation might be further increased if palpation pressure is quantified. Secondly, the examiners' decision may have been influenced by the outcome of preceding tests. It was however not practical to design the study in a way that the investigators were blinded from previous test outcomes. Thirdly, the fact that the two investigators were experienced physiotherapists with a specialisation in musculoskeletal therapy should be considered before generalising the results of this study. The investigators also received 2 hours training before conducting the testing procedures. Future research is required to investigate whether satisfactory levels of reliability can also be achieved in more novice clinicians without specific training. Finally, having demonstrated the reliability of these tests in isolation, a logical next step would be to investigate the reliability of the overall decision whether neuropathic mechanisms are present and whether subsequent interventions should target these mechanisms. Such an overall decision should be based on the patient interview and a series of clinical tests which further strengthen or weaken the hypothesis of nervous system involvement.

Reliability and validity are both essential clinometric properties of a test. This study focused on reliability, but there is increasing evidence that ULNTs have diagnostic merit $[23,26,38,45,46]$. There is however remarkably little literature on the validity of the bedside neurological examination and nerve palpation in patients with neuromusculoskeletal conditions. Future studies should concentrate on the further validation of clinical examination procedures for nerve function and mechanosensitivity.

\section{Conclusion}

Clinical tests to evaluate increased nerve mechanosensitivity and afferent/efferent function have moderate to substantial reliability. This satisfactory level of reliability in combination with the increasing evidence of diagnostic merit $[23,26,38,45,46]$ indicates that ULNTs have acceptable clinometric properties. Bearing in mind the different underlying pathophysiological mechanisms, clinicians should consider testing for both nerve function and nerve mechanosensitivity when diagnosing patients with suspected peripheral nerve lesions. However, the literature on the validity of bedside neurological examination in patients with musculoskeletal symptoms is scarce and there are no studies available which examine the validity of nerve palpation.

\section{Competing interests}

The authors declare that they have no competing interests.

\section{Authors' contributions}

$\mathrm{AB}$ designed the study, collected data and prepared the manuscript. FB and SK assisted in the design and data collection. HL and MC were involved in the design and drafting of the manuscript. $\mathrm{UH}$ and $\mathrm{LB}$ performed the statistical analysis and were involved in drafting the manuscript. All authors read and approved the final manuscript.

\section{Acknowledgements}

AS was supported by the Endeavour Europe Award and the Endeavour International Postgraduate Research Scholarship, Australia

\section{References}

I. Ropper AH, Brown RH: Adams and Victor's Principles of Neurology 8th edition. New York: McGraw-Hill, Medical Publishing Division; 2005.

2. Lee DH, Claussen GC, Oh S: Clinical nerve conduction and needle electromyography studies. J Am Acad Orthop Surg 2004, I 2:276-287.

3. Lacomis D: Small-fiber neuropathy. Muscle Nerve 2002, 26: $173-188$.

4. Hoitsma E, Reulen JP, de Baets M, Drent M, Spaans F, Faber CG: Small fiber neuropathy: a common and important clinical disorder. J Neurol Sci 2004, 227: I19-130.

5. Bove GM, Ransil BJ, Lin HC, Leem JG: Inflammation induces ectopic mechanical sensitivity in axons of nociceptors innervating deep tissues. J Neurophysiol 2003, 90:1949-1955.

6. Dilley A, Lynn B, Pang SJ: Pressure and stretch mechanosensitivity of peripheral nerve fibres following local inflammation of the nerve trunk. Pain 2005, I I 7:462-472.

7. McLellan DL, Swash M: Longitudinal sliding of the median nerve during movements of the upper limb. J Neurol Neurosurg Psychiatry 1976, 39:566-570.

8. Coppieters MW, Alshami AM, Babri AS, Souvlis T, Kippers V, Hodges PW: Strain and excursion of the sciatic, tibial, and plantar nerves during a modified straight leg raising test. J Orthop Res 2006, 24: I883-I889.

9. Gelberman RH, Hergenroeder PT, Hargens AR, Lundborg GN, Akeson WH: The carpal tunnel syndrome. A study of carpal canal pressures. J Bone Joint Surg Am 1981, 63:380-383.

10. Coppieters MW, Butler DS: Do 'sliders' slide and 'tensioners' tension? An analysis of neurodynamic techniques and considerations regarding their application. Man Ther 2008, I3:2|3-22|.

II. Spurling RG, Scoville WB: Lateral rupture of the cervical intervertebral discs: a common cause of shoulder and arm pain. Surg Gynecol Obstet 1944, 78:350-358.

12. Supik LF, Broom MJ: Sciatic tension signs and lumbar disc herniation. Spine 1994, 19:1066-1069.

13. Butler DS: The Sensitive Nervous System Edinburgh: Churchill Livingstone; 1991.

14. Elvey RL: Brachial plexus tension tests and the pathoanatomical origin of arm pain. In Aspects of Manipulative Therapy Edited by: Idczak RM. Melbourne: Lincoln Institute of Health Sciences; 1980:105-I10.

15. Maitland G: The slump test: examination and treatment. Aust J Physiother 1985, 3 I:2 15-219.

16. Byng J: Overuse syndromes of the upper limb and the upper limb tension test: a comparison between patients, asymptomatic keyboard workers and asymptomatic non-keyboard workers. Man Ther 1997, 2:157-164.

17. Grant R, Forrester C, Hides J: Screen based keyboard operation: the adverse effects on the neural system. Aust J Physiother 1995, 4 I:99- 105.

18. Kelley S, Jull G: Breast surgery and neural tissue mechanosensitivity. Aust J Physiother 1998, 44:3 I-37.

19. Yaxley G, Jull G: A modified upper limb tension test: an investigation of responses in normal subjects. Aust J Physiother 1991, 37:143-152

20. Coppieters M, Stappaerts K, Janssens K, Jull G: Reliability of detecting 'onset of pain' and 'submaximal pain' during neural 
provocation testing of the upper quadrant. Physiother Res Int 2002, 7: $146-156$

21. Coppieters MW, Stappaerts KH, Everaert DG, Staes FF: Addition of test components during neurodynamic testing: effect on range of motion and sensory responses. J Orthop Sports Phys Ther 200I, 31:226-235.

22. Heide B Van der, Bourgoin C, Eils G, Garnevall B, Blackmore M: Test-retest reliability and face validity of a modified neural tissue provocation test in patients with cervicobrachial pain syndrome. J Man Manip Ther 2006, I 4:30-36.

23. Selvaratnam PJ, Matyas TA, Glasgow EF: Noninvasive discrimination of brachial plexus involvement in upper limb pain. Spine 1994, 19:26-33.

24. Breig A, Troup JD: Biomechanical considerations in the straight-leg-raising test. Cadaveric and clinical studies of the effects of medial hip rotation. Spine 1979, 4:242-250.

25. Butler DS: The Sensitive Nervous System Unley: NOI Group Publications; 2000.

26. Wainner RS, Fritz JM, Irrgang JJ, Boninger ML, Delitto A, Allison S: Reliability and diagnostic accuracy of the clinical examination and patient self-report measures for cervical radiculopathy. Spine 2003, 28:52-62.

27. Elvey RL: Physical evaluation of the peripheral nervous system in disorders of pain and dysfunction. J Hand Ther 1997, 10:122-129.

28. Jepsen JR, Laursen LH, Hagert CG, Kreiner S, Larsen Al: Diagnostic accuracy of the neurological upper limb examination Il: relation to symptoms of patterns of findings. BMC Neurol 2006, 6: 10 .

29. Sim J, Wright CC: The kappa statistic in reliability studies: use, interpretation, and sample size requirements. Phys Ther 2005, 85:257-268

30. Kendall FP, McCreary EK, Provance PG: Muscles Testing and Function 4th edition. Baltimore: Williams and Wilkins; 1993.

31. Aminoff MJ, A GD, Simon RP: Clinical Neurology 6th edition. New York: McGraw-Hill Medical; 2005.

32. Research Randomizer [http://www.randomizer.org/]

33. Kirkwood B, Sterne J: Essential Medical Statistics Oxford: Blackwell Publishing; 2006

34. Landis JR, Koch GG: The measurement of observer agreement for categorical data. Biometrics 1977, 33:159-174.

35. Zuluaga M: Intertherapist reliability study of the brachial plexus tension test. Aust J Physiother 1986, 34:57.

36. Viikari-Juntura E: Interexaminer reliability of observations in physical examinations of the neck. Phys Ther 1987, 67:1526-1532.

37. Wainner RS, Fritz JM, Irrgang JJ, Delitto A, Allison S, Boninger ML: Development of a clinical prediction rule for the diagnosis of carpal tunnel syndrome. Arch Phys Med Rehabil 2005, 86:609-6I8.

38. Coppieters MW, Alshami AM, Hodges PW: An experimental pain model to investigate the specificity of the neurodynamic test for the median nerve in the differential diagnosis of hand symptoms. Arch Phys Med Rehabil 2006, 87:|4|2-1417.

39. Coppieters MW, Kurz K, Mortensen TE, Richards NL, Skaret IA McLaughlin LM, Hodges PW: The impact of neurodynamic testing on the perception of experimentally induced muscle pain. Man Ther 2005, 10:52-60.

40. Jepsen JR, Laursen LH, Hagert CG, Kreiner S, Larsen Al: Diagnostic accuracy of the neurological upper limb examination I: interrater reproducibility of selected findings and patterns. $B M C$ Neurol 2006, 6:8

4l. Manschot S, van Passel L, Buskens E, Algra A, van Gijn J: Mayo and NINDS scales for assessment of tendon reflexes: between observer agreement and implications for communication. J Neurol Neurosurg Psychiatry 1998, 64:253-255.

42. Waddell G, Main CJ, Morris EW, Venner RM, Rae PS, Sharmy SH, Galloway $\mathrm{H}$ : Normality and reliability in the clinical assessment of backache. Br Med J (Clin Res Ed) 1982, 284:1519-1523.

43. Jepsen J, Laursen L, Larsen A, Hagert CG: Manual strength testing in 14 upper limb muscles: a study of inter-rater reliability. Acta Orthop Scand 2004, 75:442-448.

44. Bohannon RW: Manual muscle testing: does it meet the standards of an adequate screening test? Clin Rehabil 2005 19:662-667.

45. Rubinstein SM, Pool J], van Tulder MW, Riphagen II, de Vet HC: A systematic review of the diagnostic accuracy of provocative tests of the neck for diagnosing cervical radiculopathy. Eur Spine J 2007, 16:307-319.

46. Shacklock MO: Positive upper limb tension test in a case of surgically proven neuropathy: analysis and validity. Man Ther 1996, I:I54-161.

\section{Pre-publication history}

The pre-publication history for this paper can be accessed here:

\section{http://www.biomedcentral.com/1471-2474/10/11/pre} pub
Publish with Bio Med Central and every scientist can read your work free of charge

"BioMed Central will be the most significant development for disseminating the results of biomedical research in our lifetime. "

Sir Paul Nurse, Cancer Research UK

Your research papers will be:

- available free of charge to the entire biomedical community

- peer reviewed and published immediately upon acceptance

- cited in PubMed and archived on PubMed Central

- yours - you keep the copyright 